\title{
Comparison of peak expiratory flow measurement by Mini-Wright peak flow meter and electronic spirometer in healthy elementary school children
}

\author{
Mardjanis Said, MD; Sudigdo Sastroasmoro, MD, PhD; Bambang Supriyatno, MD; Yovita Ananta, MD
}

\begin{abstract}
Objective This study aims to compare peak expiratory flow measurement by peak flow meter and electronic spirometer in healthy elementary school children.

Methods This was a cross-sectional study performed in an elementary school near Cipto Mangunkusumo hospital (SDN Pegangsaan 01). The study group consisted of healthy children aged 6-12 year old. Data regarding identity and history of illness was taken in each subject. Routine physical examination was performed and recorded. Each subject performed lung function tests by means of electronic spirometer AS-7 as well as by Mini-Wright peak flow meter. The subject should perform a minimum of three maneuvers for each method where only the best result was recorded. Method comparison test to assess agreement between two methods was employed in this study.

Results There were 10 males and 15 females enrolled in this study. None of the subjects currently have any respiratory symptoms and signs. This study found that the mean peak expiratory flow (PEF) by spirometer was $226.8 \pm 73.13 \mathrm{~L} / \mathrm{min}$ while by peak flow meter was 223.0 \pm 45.05 . Mean difference between spirometer and peak flow meter measurements is 6.2 with standard deviation of 60.82 . These values resulted in limits of agreement of -115.44 to $+127.84 \mathrm{~L} / \mathrm{min}$.

Conclusions This study finds disagreement between electronic spirometer and Mini-Wright peak flow meter in measuring peak expiratory flow, therefore these two devices cannot be used interchangeably. Mini-Wright peak flow meter still has a role in home monitoring, but the physician should interpret the results carefully. [Paediatr Indones 2004;44:248-252].
\end{abstract}

Keywords: peak expiratory flow, Mini-Wright peak flow meter, electronic spirometer, agreement

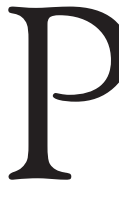
eak expiratory flow (PEF) measurement is beneficial in identifying and evaluating the airflow-limitation degree in epidemiological studies. In clinical practice, it can be useful in monitoring the progress of disease and the effects of treatment. ${ }^{1-2}$

Spirometry is a basic test useful both for measuring and for monitoring lung function, including $\mathrm{PEF}^{3}$ The electronic spirometer has been extensively used in specialists' practices. On the other hand, a simpler device, Mini-Wright peak flow meter (MWPFM), has been the most widely used device both in general practices and at home. ${ }^{4-6}$ Although it is portable, relatively easy to use, and affordable, MWPFM has limitations and disadvantages. $5,7-8$ Many studies found that MWPFM produced higher PEF values than the electronic spirometer did. ${ }^{9,10}$ Many other studies

From the Department of Child Health, Medical School, Universityof Indonesia, Jakarta, Indonesia.

Reprint requests to: Mardjanis Said MD, Department of Child Health, Medical School, University of Indonesia, Jakarta, Indonesia. Tel. 62 21-3907740, Fax. 62-21-3907743. 
also found that MWPFM was inaccurate and produced inconsistent results. ${ }^{11-15}$

This study aimed to compare peak expiratory flow measurement by peak flow meter and electronic spirometer on healthy elementary school children by performing these two measurement separately, as usually performed in practice.

\section{Methods}

This was a cross-sectional study on healthy children attending SDN Pegangsaan 01. For enrollment of the study, patients were required to be at least 6 years of age. Parental consent was obtained. The sample was drawn by random methods. ${ }^{16}$

The sample size was determined using the formula for paired groups. ${ }^{16}$ We used significance degree $(\alpha)$ of 0.05 , power $(1-\beta)$ of 0.80 , and minimal clinically important difference $(\delta)$ of $20 \%$. Standard deviation of mean difference $\left(\mathrm{s}_{\text {diff }}\right)$ was obtained by firstly doing a pilot study on 10 children. The calculation yielded 25 subjects for each group.

Data regarding identity and history of illness was taken and each subject underwent routine physical examination and lung function tests by means of electronic spirometer AS-7. It was done in standing posture with the head in a neutral erect position; nose clips were not used. Each subject was told to take a deep breath to full inflation, place the lips tightly around the mouthpiece, and blow out into the device as hard and as fast as possible until no further gas could be exhaled. The subjects should place his/her teeth around the outside of the mouthpiece and prevent his/her tongue from occluding the mouthpiece. These maneuvers should be observed by the operator to assure that the subjects adhered to the instructions. After each measurement, the equipment was prepared for the next measurement. The subjects performed a minimum of three maneuvers, of which only the best result was recorded. ${ }^{17}$

Each subject also underwent lung function test by means of Mini-Wright peak flow meter. Every subject used a different device made by same manufacturer. This portable handheld peak flow meter was used with the following guidelines. ${ }^{17}$ First, the recording needle was returned to zero. A nose clip was not required. The subject was instructed to breathe as deeply as possible and place his/her lips and teeth around the mouthpiece to make a tight seal. The subject then made a short, sharp, hard blow with an open glottis for 1 second. The subject was told not to occlude the exhaust holes on the device or to block the scale pointer by his/her hands. Each subject performed three blows with the pointer being returned to 0 between blows. The highest reading of these was recorded. If the subject coughed during the procedure, or a leak at the mouth was detected during a blow, that attempt was not included. ${ }^{17}$

We employed two statistical approaches on this study. Firstly, we performed paired t-test to detect any difference between the two measurements. A p level of $<0.05$ was considered significant. Since this test may not be able to evaluate variability in values, we also employed a second analysis proposed by Bland and Altman ${ }^{18}$ to assess agreement between two methods. We calculated the mean difference and the standard deviation of the differences $\left(s_{\text {diff }}\right)$. Then, we determined the 95\% limits of agreement, obtained from a range of mean $\pm 2 s_{\text {diff. }}$ The interpretation and determination of acceptable agreement depended upon the clinical circumstances since it cannot be defined statistically. ${ }^{18}$

The study was approved by the Committee of the Medical Research Ethics of Medical School, University of Indonesia. Data collected were processed using SPSS 11.0 computer program.

\section{Results}

There were 127 healthy children who met the inclusion criteria. Of these, twenty-five children were randomly selected consisting of 10 males and 15 females. The characteristics of subjects are shown in Table 1 . None of the subjects had any respiratory symptoms and signs.

The peak expiratory flow results of both methods are presented in Table 2. Mean difference be- 
tween spirometer and peak flow meter measurement was 6.2 with standard deviation of 60.82 . These values resulted in $95 \%$ limits of agreement of -115.4 to $+127.84 \mathrm{~L} / \mathrm{min}$.

\section{Discussion}

Peak expiratory flow (PEF) is the maximum flow achieved during a forced expiration starting from the level of maximal lung inflation. ${ }^{2}$ In monitoring the progress of a disease and the effects of treatment it is important to measure PEF as it can identify and evaluate the degree of airflow-limitation. ${ }^{2}$

In this study, we find that Mini-Wright peak flow meter overestimated $\mathrm{PEF}$ at lower rates and underestimated PEF at higher rates ( $>300 \mathrm{~L} / \mathrm{min})$. This supported findings by Hankinson et al ${ }^{10}$ and Wirjodiardjo et al. ${ }^{15}$ However, both studies found that underestimation of measurement occurs in rates higher than $600 \mathrm{~L} / \mathrm{min} .10,15$ Our study only measured PEF on elementary school children with the highest flow of $390 \mathrm{~L} / \mathrm{min}$.

Table 1. Subjects' characteristics

\begin{tabular}{lcc}
\hline & Mean(SD) & Range \\
\hline Age (year) & $9.3(1.96)$ & $6.00-12.00$ \\
Weight $(\mathrm{kg})$ & $129.5(11.71)$ & $108.6-153.7$ \\
Height $(\mathrm{cm})$ & $27.9(9.46)$ & $18.0-53.5$ \\
PEF, spirometer (L/min) & $226.8(73.13)$ & $110.0-390.0$ \\
PEF, peak flow meter (L/min) & $223.0(45.05)$ & $150.0-325.0$ \\
\hline
\end{tabular}

Although on average the MWPFM was not found to have any significant difference with the spirometer $(p=0.615)$, on individual basis this study discovered unacceptably wide limits of agreement $(-115.4$ to $+127.8 \mathrm{~L} / \mathrm{min})$ between Mini-Wright peak flow meter and spirometer measurements. This means that the MWPFM does not agree with the spirometer and therefore cannot replace the spirometer for measuring PEF. This is in accordance with recommendations made by Sly et al, ${ }^{11}$ Miller et $a l,{ }^{12}$ and McKenzie et al, ${ }^{6}$ who all found that peak flow meter produced diverse, even inconsistent values. This discrepancy was suggested to originate from nonlinear characteristics of the critical orifice within the device. ${ }^{14}$
TABle 2. Peak expiratory flow Results (L/Min): SPIROMETER VS MINI-WRIGHT PEAK FLOW METER

\begin{tabular}{|c|c|c|c|}
\hline No & Spirometer & Peak flow $r$ & meter Difference \\
\hline 1 & 110 & 200 & 90 \\
\hline 2 & 120 & 200 & 80 \\
\hline 3 & 140 & 150 & 10 \\
\hline 4 & 150 & 225 & 75 \\
\hline 5 & 160 & 225 & 65 \\
\hline 6 & 180 & 150 & -30 \\
\hline 7 & 180 & 200 & 20 \\
\hline 8 & 180 & 225 & 45 \\
\hline 9 & 180 & 225 & 45 \\
\hline 10 & 190 & 225 & 35 \\
\hline 11 & 190 & 275 & 85 \\
\hline 12 & 210 & 225 & 15 \\
\hline 13 & 220 & 300 & 80 \\
\hline 14 & 230 & 180 & -50 \\
\hline 15 & 230 & 270 & 40 \\
\hline 16 & 240 & 250 & 10 \\
\hline 17 & 250 & 225 & -25 \\
\hline 18 & 270 & 175 & -95 \\
\hline 19 & 270 & 325 & 55 \\
\hline 20 & 280 & 225 & -55 \\
\hline 21 & 300 & 250 & -50 \\
\hline 22 & 320 & 275 & -45 \\
\hline 23 & 340 & 250 & -90 \\
\hline 24 & 340 & 275 & -65 \\
\hline 25 & 390 & 300 & -90 \\
\hline Mean & 226.80 & 233.00 & 6.20 \\
\hline SD & 73.13 & 45.05 & 60.82 \\
\hline \multicolumn{4}{|c|}{$p=0.615^{*}$} \\
\hline
\end{tabular}

Sly et $a^{11}$ in their study found that peak flow meters do not only give inaccurate absolute values, but may also not be as effective as spirometers in tracking changes in lung function in children with asthma. The measurements are likely to differ depending on the brand of peak flow meter used. Another study also concluded that interchanging devices may result in variability of results, because of the lack of comparability between different devices. ${ }^{6}$ In this study, we only used one type of peak flow meter made by same manufacturer. Nevertheless, we used different peak flow meter devices for different individuals, which might contribute to a slight difference as each measurement device, just like other scales, 
also needs calibration. On the other hand, we only used one spirometer for all subjects, which eliminated the need for calibration. In clinical settings, patients therefore are recommended to have and to use their own device every time they measure their PEF, and even bring it to the clinic on regular visits. ${ }^{6,11}$ Thus, if a change is found in patients who use their personal device, the change is real and is more valuable than when they use a different device.

Although this study found disagreement between spirometer and Mini-Wright peak flow meter, we did not imply that MWPFM should not be used in home practice. We suggested that the values obtained in clinical practice should be interpreted carefully, particularly in adjusting medication doses for asthma, and as a guide for admission or discharge of asthmatic patients from the emergency room. ${ }^{11,13}$

Furthermore, a physician has to determine the child's "personal best" PEF by observing it for 1 to 2 weeks at a time when the child is well. This value can then be utilized as a basis for comparison during asthma attacks. ${ }^{14}$ Patients should also be encouraged to take their peak flow meter to the asthma clinic to check their test technique, the measurements, and any obvious damage. The device should be calibrated regularly and be replaced every three years. ${ }^{6}$

In conclusion, this study found disagreement between electronic spirometer and MiniWright peak flow meter in measuring peak expiratory flow, therefore these two devices can not be used interchangeably. Mini-Wright peak flow meter still has a role in home monitoring, but the physician should interpret the results carefully. Patients should have their own personal device which they should bring to the clinic on regular PEF assessments. Physicians should also perform regular technique checking, calibration and replacement whenever necessary.

\section{References}

1. Quanjer PH, Lebowitz MD, Greff I, Miller MR, Pedersen OF. Peak expiratory flow: conclusions and recommendatinos of a Working Party of the Euro- pean Respiratory Society. Eur Respir J Suppl 1997;24(suppl):2-8.

2. Sly PD, Flack FS. Lung function. In: Silverman M, ed. Childhood asthma and other wheezing disorders. $2^{\text {nd }}$ ed. London: Arnold publishers; 2002. p. $125-43$

3. No authors listed. Peak flow meter use in asthma management. Thoracic Society of Australia and New Zealand. Med J Aust 1996;164:727-30.

4. Peak expiratory flow measured with the Mini Wright Peak Flow Meter in children. Sanz J, Martorell A, Saiz R, Alvarez V, Carrasco JI. Pediatr Pulmonol 1990;9:86-90.

5. No authors listed. Measuring pulmonary function in practice. Practitioner 2002; Jun:445.

6. McKenzie B, Barrett TC, Spencer DA, Garbe B. Accuracy of peak flow meters: don't interchange devices. BMJ 1994;308:917

7. Clinical presentation and ongoing clinical and physiologic assessment of asthma in children. In: Taussig LM, Landau LI, Le Souef PN, Morgan WJ, Martinez FD, Sly PD, eds. Pediatric respiratory medicine. St. Louis: Mosby; 1999. p. 943-5

8. Castile RG. Pulmonary function testing in children. In: Chernick V, Boat TF, eds. Kendig's disorders of the respiratory tract in children. $6^{\text {th }}$ ed. Philadelphia: WBSaunders Co; 1998. p.196-214

9. Jones KP, Mullee MA. Lung function measurement in general practice: a comparison of the Escort spirometer with the Micromed turbine spirometer and the miniWright peak flow meter. Respir Med 1995; 89:657-63

10. Hankinson, JL, Filios MS, Kinsley KB, Petsonk EL. Comparing Mini Wright and spirometer measurement of peak expiratory flow. Chest 1995;108: 407-10.

11. Sly PD, Cahill P, Willet K, Burton P. Accuracy of mini peak flow meters in indicating changes in lung function in children with asthma. BMJ 1994;308:572-4.

12. Miller MR, Ouanjer PH. Peak flow meters: a problem of scale. BMJ 1994;308:548-9.

13. Brusasco V. Usefulness of peak expiratory flow measurements: is it just a matter of instrument accuracy? Thorax 2003;58:375-6

14. Sly PD, Hayden MJ, Morgan WJ. Lung function in cooperative subjects. In: Taussig LM, Landau LI, Le Souef PN, Morgan WJ, Martinez FD, Sly PD, editors. Pediatric respiratory medicine. St. Louis: Mosby; 1999. p. 205-211

15. Wirjodiardjo M, Said M, Boediman HI. Perbandingan hasil pengukuran peak flow rate antara Mini Wright peak flow 


\section{Paediatrica Indonesiana}

meter dan spirometer elektronik pada anak. MKI 1992;42:575-85.

16. Sastroasmoro S, Ismael S. Dasar-dasar metodologi penelitian klinis. $2^{\text {nd }}$ ed. Jakarta: CV Sagung Seto; 2002. p. 269, 384
17. British Thoracic Society. Guidelines for the measurement of respiratory function. Resp Med 1994;88:163-94.

18. Altman, DG. Practical Statistics for Medical Research. London: Chapman and Hall; 1991. p. 396-439. 